\title{
Trait anxiety modulates supraliminal and subliminal threat: Brain potential evidence for early and late processing influences
}

\author{
Wen Li, Richard E. Zinbarg, And Ken A. Paller \\ Northwestern University, Evanston, Illinois
}

\begin{abstract}
Analysis of threat is thought to involve a "quick and dirty" stage in conjunction with slower processing that is more complete. We investigated both types of threat analysis by recording brain potentials in response to threat and neutral words. Personality testing was used to identify participants who were either high or low in trait anxiety (TA). An observed enhancement of occipital P1 potentials to threat words during an emotional Stroop task was interpreted as a signal of unconscious processing, since it was early, independent of whether word exposure was subliminal or supraliminal, and more prominent the higher the level of TA. Later positive potentials were also enhanced for threat versus neutral words, but the amplitude enhancement increased with higher TA only in the subliminal condition. These results suggest that unconscious analysis of threat is intensified in those prone to anxiety, as is a later stage of threat processing subject to dynamic interactions between automatic and strategic influences.
\end{abstract}

Neural mechanisms for efficiently extracting and processing signals of impending danger have critical survival value. Indeed, research has demonstrated privileged threat processing from behavioral, physiological, and neuroimaging perspectives. Such processing is more salient among anxious than among nonanxious individuals and has been posited to be fast, automatic, and even unconscious (for reviews, see Damasio, 1994; Davidson, 1998; Dolan, 2002; Lang, Bradley, \& Cuthbert, 1997; Öhman \& Mineka, 2001; J. M. G. Williams, Watts, MacLeod, \& Mathews, 1997). In addition, it has been conjectured that analysis of threat information includes a "quick and dirty" phase that can promote autonomic arousal and prepare the body for action, followed by a more deliberate and accurate phase that can promote strategic responses to threat (for reviews, see LeDoux, 1995, 1996; Öhman, 1979, 1993). In this study, we investigated threat processing with regard to (1) its automatic or unconscious nature, (2) its temporal dynamics, and (3) the influence of anxiety, thus combining multiple perspectives that together can shed new light on threat processing.

\section{Automatic Processing of Threat at Early Stages}

It is well documented that threat information leads to augmented amygdala activation and that such activation can be automatic (for reviews, see Davis \& Whalen, 2001; Dolan \& Vuilleumier, 2003). Neuroimaging research has also suggested that threat information leads to greater activation than neutral information in visual association cortex (see, e.g., Pessoa, McKenna, Gutierrez, \& Ungerleider, 2002; Vuilleumier, Armony, Driver, \& Dolan, 2003; also see Phelps, 2006, for a review), which may reflect a boost in visual analysis caused by input from the amygdala (Vuilleumier, Richardson, Armony, Driver, \& Dolan, 2004). These data thus support the notion of automatic preferential perception of threat.

Nevertheless, these data are silent about the temporal aspects of threat processing. Electrophysiological measures with high temporal resolution, on the other hand, have provided insights into the temporal nature of enhanced analysis of threat. The occipital or occipitoparietal P1 - a visual event-related potential (ERP) peaking around $100 \mathrm{msec}$ poststimulus and reflecting visual perceptual processing (Gomez, Clark, Fan, Luck, \& Hillyard, 1994; Mangun, Hillyard, \& Luck, 1993) - has attracted special attention from researchers. Several studies revealed that P1 differentiated threat and nonthreat faces or pictures as early as $80 \mathrm{msec}$ after stimulus onset (Pizzagalli et al., 2002; Pizzagalli, Regard, \& Lehmann, 1999; Pourtois, Grandjean, Sander, \& Vuilleumier, 2004; Smith, Caccioppo, Larsen, $\&$ Chartrand, 2003). Pourtois et al. localized the source of this $\mathrm{P} 1$ component in extrastriate cortex. In line with these findings, magnetoencephalographic results showed differential processing of emotional versus neutral faces in occipital cortex $120 \mathrm{msec}$ after stimulus onset (Halgren, Raij, Marinkovic, Jousmaki, \& Hari, 2000). These studies provided clear evidence for the "quickness" of emotion processing, although the automaticity of such processing was not directly manipulated.

For threatening stimuli, unconscious processing has particularly important implications for anxiety (see, e.g., Etkin et al., 2004; Fox, 2002; Mathews \& MacLeod,

W. Li, wenli@northwestern.edu 
1985; Öhman \& Soares, 1994). Unconscious processing of threat cues may contribute to the experience perceived as free-floating anxiety in generalized anxiety disorder (Mathews \& MacLeod, 1986) and may be responsible for panic attacks that occur without awareness of threat. An anxiety patient, for instance, may experience a "spontaneous" panic attack following the unconscious processing of certain bodily sensations such as a palpitation (Clark, 1988). Therefore, beyond the issue of whether or not threat processing occurs automatically, it is important to know whether it can occur unconsciously.

\section{Automatic and Strategic Processing of Threat at Later Stages}

Brain potentials also demonstrated enhanced emotion processing at later stages: A reliable dissociation between emotional and neutral stimulus processing often emerges at about $400 \mathrm{msec}$ poststimulus and lasts for several hundred milliseconds. These effects appear in late positive ERPs, sometimes referred to as $P 3$ potentials, which are augmented for negative and positive stimuli relative to neutral stimuli (Cuthbert, Schupp, Bradley, Birbaumer, \& Lang, 2000; Dietrich et al., 2000; Eimer \& Holmes, 2002; Holmes, Vuilleumier, \& Eimer, 2003; LaBar et al., 1999; Liddell, Williams, Rathjen, Shevrin, \& Gordon, 2004; Schupp et al., 2000; Schupp, Junghöfer, Weike, \& Hamm, 2003; Schupp et al., 2004). These findings echoed those from a group of previous studies that also reported emotion effects on late positive potentials in similar time intervals (Halgren \& Marinkovic, 1995; Ito, Larsen, Smith, \& Cacioppo, 1998; Johnston, Miller, \& Burleson, 1986; Palomba, Angrilli, \& Mini, 1997). Halgren and Marinkovic posited that these potentials were associated with conscious processing. The association between late positive potentials and conscious processing has also been suggested in many other studies (e.g., Beck, 1975; Donchin \& Coles, 1988; Hillyard, Squires, Bauer, \& Lindsay, 1971; Ritter \& Ruchkin, 1992).

Does this stage of analysis also involve automatic emotion processing? Notably, in three studies, $\mathrm{P} 3$ effects during semantic or structure-identification tasks were examined, eliminating the need for the affective judgments required in the studies cited above. These studies yielded equivocal evidence about whether or not late emotion processing occurs involuntarily: One study showed P3 enhancement to emotional in comparison with neutral adjectives (Naumann, Bartussek, Diedrich, \& Laufer, 1992), whereas the others failed to show such an effect (Holmes et al., 2003; Naumann, Maier, Dietrich, Becker, \& Bartussek, 1997). Hence, the automaticity of delayed emotion processing remains unclear.

\section{Threat Processing in Anxious Individuals}

An association between anxiety and the preferential processing of emotion has been suggested in many behavioral and psychophysiological studies (Lang, Davis, \& Öhman, 2000; J. M. G. Williams, Mathews, \& MacLeod, 1996). Specifically, preferential processing of threat was more salient among anxious than among nonanxious peo- ple, and in some studies (e.g., Bradley, Mogg, Millar, \& White, 1995; Mathews \& Sebastian, 1993; Van den Hout, Tenney, Huygens, Merckelbach, \& Kindt, 1995) the bias was seen inversely, in nonanxious people. Therefore, it is important to consider anxiety and preferential threat processing in tandem. To this end, an analysis of the temporal characteristics of threat processing can provide relevant insights. A prominent proposal about anxiety is that it influences early and late processing differently in that threat processing in anxious individuals is facilitated early but avoided at a later stage (for reviews, see Mathews \& MacLeod, 1994; J. M. G. Williams, et al., 1997). However, this proposal has rarely been evaluated with direct observations that would allow the time course of relevant information processing to be delineated. In the present study, we took anxiety into account by obtaining measures of trait anxiety (TA), a personality trait that predicts one's sensitivity to threat and tendency to become anxious, and measured ERPs to provide data concerning the temporal profile of threat processing.

As was done in many prior studies of threat processing, we applied the emotional Stroop paradigm. Differential interference in color naming by emotional versus neutral words may indicate that emotion processing automatically takes resources away from color naming. Our paradigm provided additional leverage for testing automaticity by including subliminal trials. Our analyses of ERP responses to subliminal and supraliminal words in the emotional Stroop paradigm focused on two time intervals when key effects were observed. An early occipital component (P1) and a relatively late component (P3) - corresponding to early and late stages, respectively - can provide evidence pertinent to different hypotheses about threat processing. An enhanced P1 to threat words versus neutral words, even when the words are subliminal, would provide evidence that preferential threat processing was early and unconscious. Differential P3 to threat and to neutral words could implicate automatic or strategic aspects of late threat processing, depending on comparisons between subliminal and supraliminal conditions. Furthermore, we planned to examine possible associations between ERPs and degree of TA with respect to the hypothesis that threat processing is influenced by TA at different stages.

\section{METHOD}

\section{Participants}

Right-handed native English speakers were selected from among 160 college students on the basis of their scores on the Behavioral Inhibition Scale (BIS; Carver \& White, 1994). A preliminary selection included the 21 students with the lowest scores (bottom 13\%, corresponding to BIS scores of 16 and lower) and the 19 students with the highest scores (top 12\%, corresponding to BIS scores of 23 and higher). The study was explained to all the participants, and their written consent was obtained. The participants received class credit for participating in the experiment.

Five to 8 weeks after the initial BIS assessment, these 40 participants completed the BIS a second time. BIS scores from the two assessments were averaged. In this way, state anxiety and other sources of measurement error (vis-à-vis TA) that can contribute to variance in BIS scores at each administration were averaged out, providing 
a better measure of the participants' levels of TA. (In a subsidiary analysis, we relied on BIS scores from only the second assessment and obtained findings compatible with those reported below.)

Seven participants were excluded from the analysis because of concerns that conscious word perception might have occurred in the subliminal condition (see below). Another 3 participants were excluded due to incomplete data. The final sample thus comprised 30 participants, 14 in the high-TA group and 16 in the low-TA group.

\section{Behavioral Inhibition Scale (BIS)}

The BIS consists of seven items (e.g., I worry about making mistakes; Criticism or scolding hurts quite a bit) rated on a scale ranging from 1 (very little) to 5 (very much). In comparison with other scales (e.g., Spielberger, 1983; Taylor, 1953), the BIS possesses stronger predictive validity (Carver \& White, 1994; Zinbarg \& Mohlman, 1998). The BIS also has adequate reliability, with estimates of .74 and .66 for the alpha coefficient and test-retest reliability, respectively (Carver \& White, 1994). In the present study, these indices also demonstrate satisfactory reliability; the alpha coefficients for the first and second assessments were .83 and .85 , respectively, and test-retest reliability between the two assessments was .80 ( $p<$ $.001)$.

\section{Stimuli}

We collected 190 neutral words and 160 threat words from several sources (Bradley \& Mathews, 1983; Mathews, Mogg, May, \& Eysenck, 1989; www.psy.uwa.edu.au/user/labs/cogemo/atrain. $\mathrm{htm}$ ). We excluded some of these words on the basis of affective valence ratings obtained from 12 undergraduates, using a scale of 1 (extremely negative) to 9 (extremely positive). We did not obtain ratings of threat level because of the challenge this would pose and because these words had already been identified by experts as neutral or threatening. The mean valence rating was 5.09 for the 48 selected neutral words and 2.72 for the 48 selected threat words. Words contained 5-10 letters (threat and neutral words were matched for length, at 6.73 and 6.79 letters, respectively). Threat and neutral word frequencies (Johansson \& Hofland, 1989) were matched $(M \mathrm{~s}=21.78$ and 24.00 occurrences per million, respectively). Each of the 96 words had a unique stem that could be completed by at least one alternative word with a higher frequency than the test word. These words were divided into three 32-word sets (listed in Appendix A). Sets included equal proportions of threat and neutral words matched for word frequency, word length, and affective valence (see Appendix B for the mean word length and mean word frequency of each set). Assignment of word set to condition (subliminal, supraliminal, or baseline) was counterbalanced across subjects.

\section{Procedure}

The participant sat in a dimly lit, sound-attenuated chamber facing a CRT monitor $140 \mathrm{~cm}$ away from his or her eyes. The experimenter and the participant communicated over an intercom. Words were presented on the monitor covering an average horizontal visual angle of $1.4^{\circ}$. The mask was a string of symbols (\#\&\&\#\#\&\&) that were somewhat larger than the letters and subtended a horizontal visual angle of $2.2^{\circ}$ to adequately cover the space occupied by the words. In both the emotional Stroop task and the stem-completion task described below, three types of trials were included: words presented subliminally (subliminal condition), words presented supraliminally (supraliminal condition), and strings of symbols (symbol condition). Trials in these conditions were presented in a randomly intermixed fashion.

Perceptual threshold determination. Each individual's perceptual threshold was assessed to determine the exposure duration to be used for subliminal trials. The participants were asked to identify words presented very briefly and rapidly replaced by a mask of symbols (\#\&\&\#\#\&\&). These words included six threat words (hatred, scare, bleed, ashamed, hazard, and conflict) and six neutral words (variable, fetch, radar, enlarge, marble, and ballot), none of which was used again in the experiment. Words were presented in a white font on a black background. The participants were asked to report a word on every trial even if they felt they did not see it. Stimulus onset asynchrony (SOA), the interval between onset of a subliminal word and onset of the mask, was initially set at $8.3 \mathrm{msec}$ and increased in steps of $8.3 \mathrm{msec}$ until correct report of the word.

The perceptual threshold for a subject was defined as the shortest SOA at which any word was identified. The average threshold was $46.5 \mathrm{msec}(S D=10.9)$. Threshold was unaffected by the participants' TA, word valence, or the interaction of the two factors $(p \mathrm{~s}>.1)$. To restrict conscious awareness, below-threshold SOAs were selected for subliminal trials as follows: (1) $25 \mathrm{msec}$ for participants with thresholds of 33.3-41.7 msec (none were lower) and (2) $30 \mathrm{msec}$ for participants with thresholds above $41.7 \mathrm{msec}$. Two screen refresh rates $(100$ and $120 \mathrm{~Hz})$ were used to allow for these two SOAs. In both cases, the SOA comprised three refresh cycles - the first two for word stimuli and the third for the fixation cross-prior to the onset of the mask. The SOA used in the emotional Stroop task was thus at least 25\% lower than the threshold. In the final group of 30 participants, assigned SOA was not correlated with TA.

Emotional Stroop task. After threshold determination, emotional Stroop trials were administered. In subliminal trials, a word was presented in one of three colors (yellow, blue, and green, which were presented with equiprobability and equated for luminance) followed 25 or $30 \mathrm{msec}$ later by the mask in the same color for 410 or $408.3 \mathrm{msec}$ (the latter number rounded to 410 henceforth). In supraliminal trials, words were presented in one of the three colors for $410 \mathrm{msec}$. In the symbol condition, a mask was presented for $410 \mathrm{msec}$ in one of the three colors. Intertrial intervals varied randomly from 2,010 to $2,610 \mathrm{msec}$. A total of 108 trials were administered in seven blocks for each of five conditions: subliminal neutral, subliminal threat, supraliminal neutral, supraliminal threat, and symbol. Every word was presented six or seven times. The participants were asked to report the color of every stimulus by pressing a corresponding button as quickly as possible. The participants were told to use their middle three fingers to press the buttons. They were also instructed to pay attention to the color of the stimuli and ignore word meaning. Prior to ERP recordings, there were 20-30 practice trials covering all five conditions (with subliminal and supraliminal words from the corresponding sets used subsequently), which allowed the participants to become familiar with the procedure.

Stem completion task with awareness check. In this phase of the experiment, the participants' lack of awareness of subliminal words was checked and completion priming was measured. The trial-by-trial assessment of awareness of words in the subliminal condition was important because thresholds may have changed due to adaptation and word repetition during the emotional Stroop task. Each of the words from the emotional Stroop task was presented once again in the same manner. After each stimulus, the question "What's the word?" was shown, and the participants were instructed to either report the word from that trial if they could or say "no." They were strongly encouraged to guess the word if they had any idea what it could be. Absence of conscious awareness was operationally defined in this study as total failure to report masked words. Seven participants correctly reported one or more words in the subliminal condition, and their data were excluded. For this purpose, subliminal words with suffixes added (e.g., feathers, wounded, suffering) were counted as correctly reported words.

In each trial, word stem completion followed the awareness check. Priming was measured on the basis of the participants' attempts to 
complete a matching three-letter word stem on each trial. Priming results are reported in Li, Paller, and Zinbarg, in press).

\section{ERP Procedure}

ERPs were recorded using tin electrodes embedded in an elastic cap (at Fpz, Fz, Cz, Pz, Oz, Fp1, Fp2, F3, F4, F7, F8, C3, C4, T3, $\mathrm{T} 4, \mathrm{~T} 5, \mathrm{~T} 6, \mathrm{P} 3, \mathrm{P} 4, \mathrm{O} 1$, and $\mathrm{O} 2$, according to the international 10-20 system; Jasper, 1958). Electrooculographic (EOG) recordings were obtained with three additional tin electrodes, one located below the left eye (V-EOG) and two lateral to the right and left eyes (H-EOGs). Impedance was reduced below $5 \mathrm{~K} \Omega$. Signals were amplified with a $0.05-$ to $100-\mathrm{Hz}$ band pass and digitized at $1000 \mathrm{~Hz}$. The V-EOG channel was referenced to Fp1. All EEG channels used the right mastoid as the reference. For artifact rejection, a cutoff of -75 to $75 \mu \mathrm{V}$ was used for all channels. Trials with artifacts due to eyeblinks or movements were excluded prior to averaging.

\section{Data Analysis}

Interference scores were calculated by subtracting the mean reaction time (RT) in neutral word trials from the mean RT in threat word trials. Trials with RTs shorter than $300 \mathrm{msec}$ or longer than $1,000 \mathrm{msec}$ were excluded from the analysis. Accuracy data were also analyzed.

We examined P1 in the occipital region (see, e.g., Halgren et al., 2000; Pizzagalli et al., 2002; Pizzagalli et al., 1999) and P3 along the midline (see, e.g., Cuthbert et al., 2000; Schupp et al., 2000). Mean amplitudes for these components were obtained over intervals centered on the average peak latencies observed from grand average waveforms. These intervals were $100-160 \mathrm{msec}$ for $\mathrm{P} 1(\mathrm{Oz})$ and 300-500 msec for P3 (Fz, Cz, and Pz). Mean amplitudes for these components were submitted to separate statistical analyses.

ERP waveforms were computed for two averaging epochs: from $250 \mathrm{msec}$ prior to stimulus onset to $350 \mathrm{msec}$ after stimulus onset, and from $250 \mathrm{msec}$ prior to stimulus onset to $600 \mathrm{msec}$ after stimulus onset. Given that many blinks occurred shortly after $350 \mathrm{msec}$, the averaging epoch from -250 to $350 \mathrm{msec}$ maximized the signalto-noise ratio for P1 analyses. The other epoch was used to cover the 300-500-msec window. ERPs were averaged for the five conditions (subliminal threat words/neutral words, supraliminal threat words/ neutral words, and pure symbols), and the average numbers of accepted trials were approximately 102 and 94 per condition (i.e., $6 \%$ and $13 \%$ rejection rates, respectively) for the short and long epochs, respectively.

Data were submitted to repeated measures multiple linear regression analysis. The TA measure (BIS scores averaged across the first and second assessments) did not cluster into two distinct groups but, rather, showed a continuous distribution. Regression analysis is generally superior to ANOVA in maximizing power when a continuously measured independent variable is included (West, Aiken, $\&$ Krull, 1996). We therefore used linear regression with TA as a continuous independent variable. ${ }^{1}$ An alpha value of .05 was used as the statistical significance level. To protect from Type I error due to multiple comparisons, we conducted separate analyses only when overall effects in the omnibus analysis were significant.

\section{RESULTS}

\section{Behavioral Results}

A planned comparison between symbol trials and word trials, collapsed across the two exposure types and the two word types, showed an overall delay in color naming for words in comparison with color naming for symbols. Responses were significantly slower for words (mean $\mathrm{RT}=560 \mathrm{msec}, S D=75)$ than for symbols (mean RT $=$ $551 \mathrm{msec}, S D=76)[t(29)=2.95, p<.01]$. Next, we conducted a repeated measures multiple regression analysis of color naming RT during word trials on BIS score, word type (threat vs. neutral), and exposure type (subliminal vs. supraliminal). Word type and exposure interactively affected RT $[F(1,28)=5.40, p<.05]$. This interaction was driven by slower responses to neutral words (mean RT $=$ $562 \mathrm{msec}, S D=77$ ) than to threat words (mean RT = $557 \mathrm{msec}, S D=76$ ) in the subliminal condition [this difference approached significance: $t(29)=1.87, p=.07]$ and an opposite trend in the supraliminal condition (for neutral words, mean RT $=559 \mathrm{msec}, S D=77$; for threat words, mean RT $=564 \mathrm{msec}, S D=76)[t(29)=1.66, p=$ $.11]$. The other effects were not significant $(p \mathrm{~s}>.05)$.

Accuracy did not differ among the five conditions, nor was it affected by TA independently or interactively with word valence or exposure ( $p \mathrm{~s}>.05)$. The means (and $S D \mathrm{~s})$ were $4.85 \%$ (.03), $4.44 \%$ (.03), $4.63 \%$ (.03), $4.76 \%$ (.03), and $4.69 \%$ (.03) for the subliminal neutral, subliminal threat, supraliminal neutral, supraliminal threat, and symbol conditions, respectively.

\section{ERP Results}

Occipital P1. BIS scores and word valence interactively affected P1 amplitude recorded at $\mathrm{Oz}[F(1,28)=5.26$, $p<.05]$, as revealed by a repeated measures multiple regression analysis of P1 amplitude on BIS score, word type (threat vs. neutral), and exposure (sub- vs. supraliminal). Figure 1 demonstrates that as BIS scores increased, P1 amplitude differences (threat - neutral) increased $[r=$ $.40, p<.05] .^{2}$ Figure 2 shows ERP waveforms acquired at $\mathrm{Oz}$ for participants at the lowest $25 \%$, those at the highest $25 \%$, and those in the middle $50 \%$ of the BIS score distribution. Neither exposure nor its interactions with word type and BIS score significantly influenced P1 amplitude $(p \mathrm{~s}>.05)$.

P1 peak latency was measured in 25 participants, whereas distinct P1 peaks in the interval of 100-160 msec

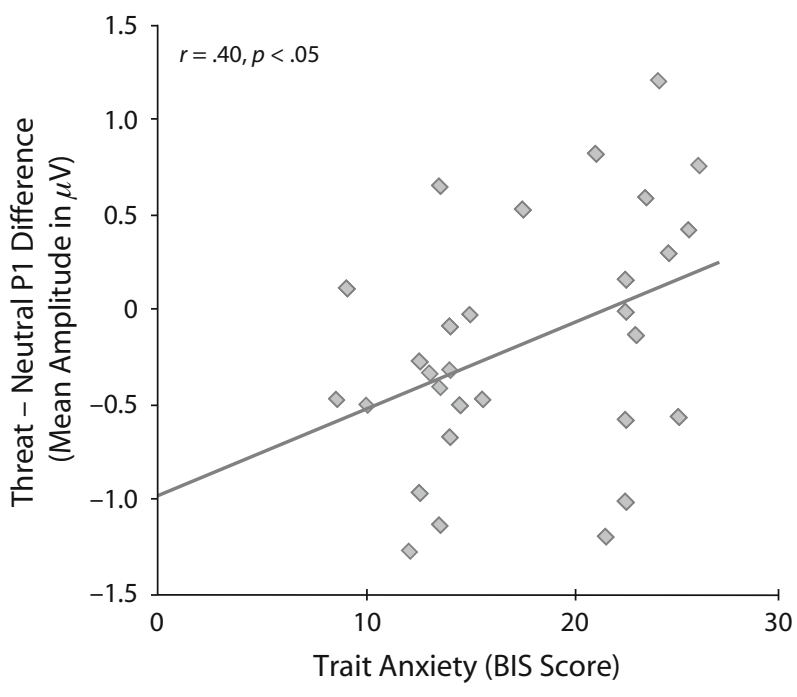

Figure 1. Positive association between differential P1 (threat - neutral) and trait anxiety. P1 amplitudes were computed by combining supraliminal and subliminal trials. 


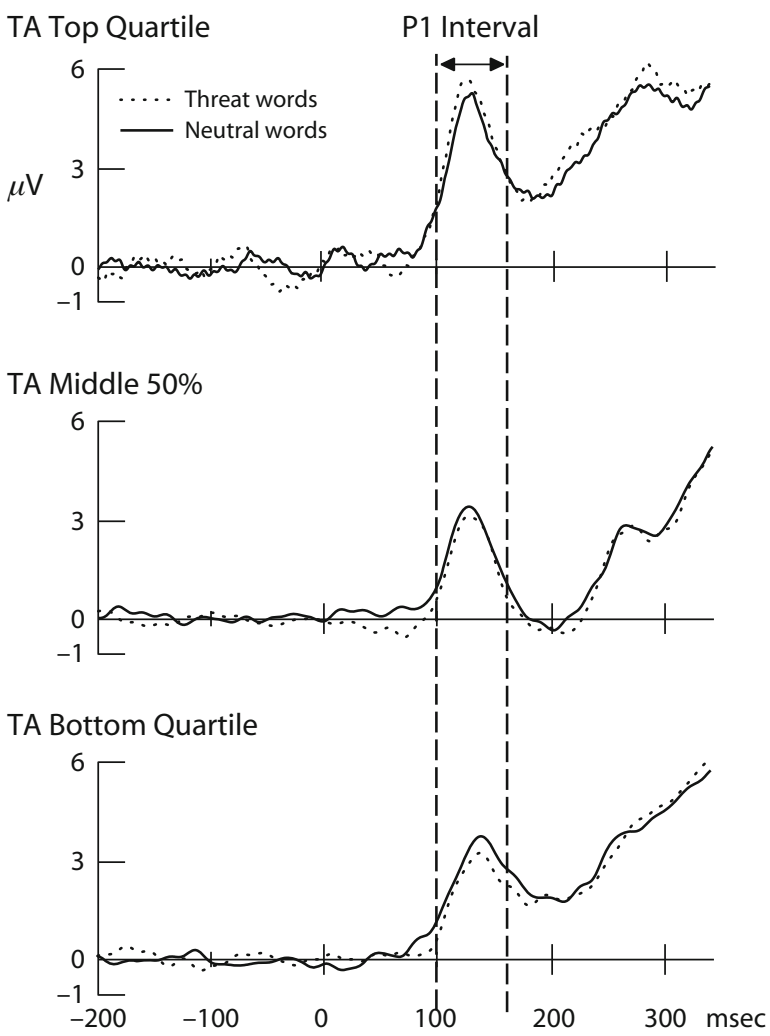

Figure 2. ERP waveforms to neutral and threat words recorded at $\mathrm{Oz}$ collapsed across subliminal and supraliminal conditions. $\mathrm{A}$ 250-msec prestimulus baseline was used in the analysis, although only 200 msec of baseline are shown here. Segregating participants based on trait anxiety (TA) demonstrates the tendency for larger P1 differences (threat $>$ neutral) in highly anxious participants. P1 to threat and neutral words measured, respectively, $3.97(S D=2.39)$ and $3.60(S D=2.61) \mu \mathrm{V}$ for the top quartile, $1.95(S D=1.85)$ and $2.21(S D=1.51) \mu \mathrm{V}$ for the middle $50 \%$, and $2.17(S D=2.02)$ and $2.69(S D=2.19) \mu \mathrm{V}$ for the bottom quartile of TA.

were not observed in the remaining participants. No reliable effects of BIS score, word type, or exposure on these latency measures were observed $(p \mathrm{~s}>.05)$.

Midline P3. P3 amplitudes recorded at three midline locations (Figure 3 ) were entered into the primary analysis. Results pertinent to our hypotheses are presented.

A valence effect on P3 was established, since threat words elicited significantly greater $\mathrm{P} 3$ amplitudes than did neutral words $[F(1,28)=8.57, p<.01]$. The effect was largest at the $\mathrm{Cz}$ electrode, where $\mathrm{P} 3$ measured 4.35 and $3.71 \mu \mathrm{V}$ for threat and neutral words, respectively. Figure 3 indicates that the valence effect was present for both supraliminal and subliminal words, yet it exhibits an anterior distribution for supraliminal words and a posterior distribution for subliminal words. This effect was confirmed by a significant three-way (valence $\times$ electrode location $\times$ exposure) interaction $[F(2,27)=11.86, p<$ $.001]$, with the valence effect for subliminal trials at $\mathrm{Cz}$ and $\mathrm{Pz}[t \mathrm{~s}(29)>2.51, p \mathrm{~s}<.05]$ and that for supraliminal trials at $\mathrm{Fz}$ and $\mathrm{Cz}[t \mathrm{~s}(29)>2.64, p \mathrm{~s}<.05]$. Topographies of the valence effects for subliminal and supraliminal con- ditions were compared following root mean square normalization (McCarthy \& Wood, 1985), which confirmed that valence effects for these two conditions had significantly different scalp distributions $[F(20,700)=3.581$, $p<.001]$.

BIS as a modulator of the valence effect was suggested by a significant four-way (valence $X$ electrode location $X$ exposure $\times$ BIS) interaction $[F(2,27)=6.32, p<.01]$. In the subliminal condition, a significant valence $\times$ location $\times$ BIS interaction was indicated $[F(2,27)=10.11$, $p=.001]$, which was driven by a significant interaction between valence and BIS at $\mathrm{Cz}$ only $[F(1,28)=5.36, p<$ $.05]$. That is, higher TA was associated with a greater valence effect on $\mathrm{P} 3$ at $\mathrm{Cz}$ than at any other location $(r=$ .41). In contrast, in the supraliminal condition, there was no significant modulatory effect of BIS on the valence effect at any location $(p s>.1)$.

P3 amplitudes were also found to be greater in the subliminal than in the supraliminal condition $[F(1,28)=$ $26.10, p<.001]$. These amplitude differences were greater at $\mathrm{Fz}$ than at $\mathrm{Cz}$ or $\mathrm{Pz}[F(2,28)=8.43, p=.001]$. In grand average ERPs, the peak amplitude in the subliminal condition appeared at an earlier latency than the peak amplitude in the supraliminal condition (Figure 3).

\section{Correlation Between RTs and ERPs}

Given the possibility that $\mathrm{P} 3$ potentials reflect some aspect of conscious information processing, we examined between-subjects correlations between color naming RTs and P3 amplitudes to threat and neutral words in both sub- and supraliminal conditions. Since P3 was affected by word valence both sub- and supraliminally at $\mathrm{Cz}$, we focused on the association between RT and P3 amplitude at this particular location. Generally, there were reliable associations between RT and P3 amplitude across both exposure conditions and word types. In the supraliminal condition, P3 amplitudes and RTs were inversely correlated for threat and neutral trials $(r=-.42, p<.01$ and $r=-.43, p<.01$, respectively). In the subliminal condition, P3 amplitudes and RTs were also inversely correlated, albeit not quite as strongly, for threat and neutral trials $(r=-.34, p=.08$ and $r=-.41, p<.05$, respectively). In contrast, none of the correlations between RT and P1 amplitudes was significant $(r \mathrm{~s} \leq .20, p \mathrm{~s}>.1)$. Taken together, these results provided support for the association between $\mathrm{P} 3$ and task-related processing.

\section{DISCUSSION}

In this study, ERP measures delineated the time course of threat processing and suggested that individual differences in TA modulate preferential processing of threat at multiple stages. Whereas early processing can often be attributed to automatic analysis of sensory input, late processing is commonly thought to be more amenable to strategic influences. Additional theoretical leverage for automatic and strategic processing was gained here by contrasting responses to subliminal input with those to supraliminal input. 

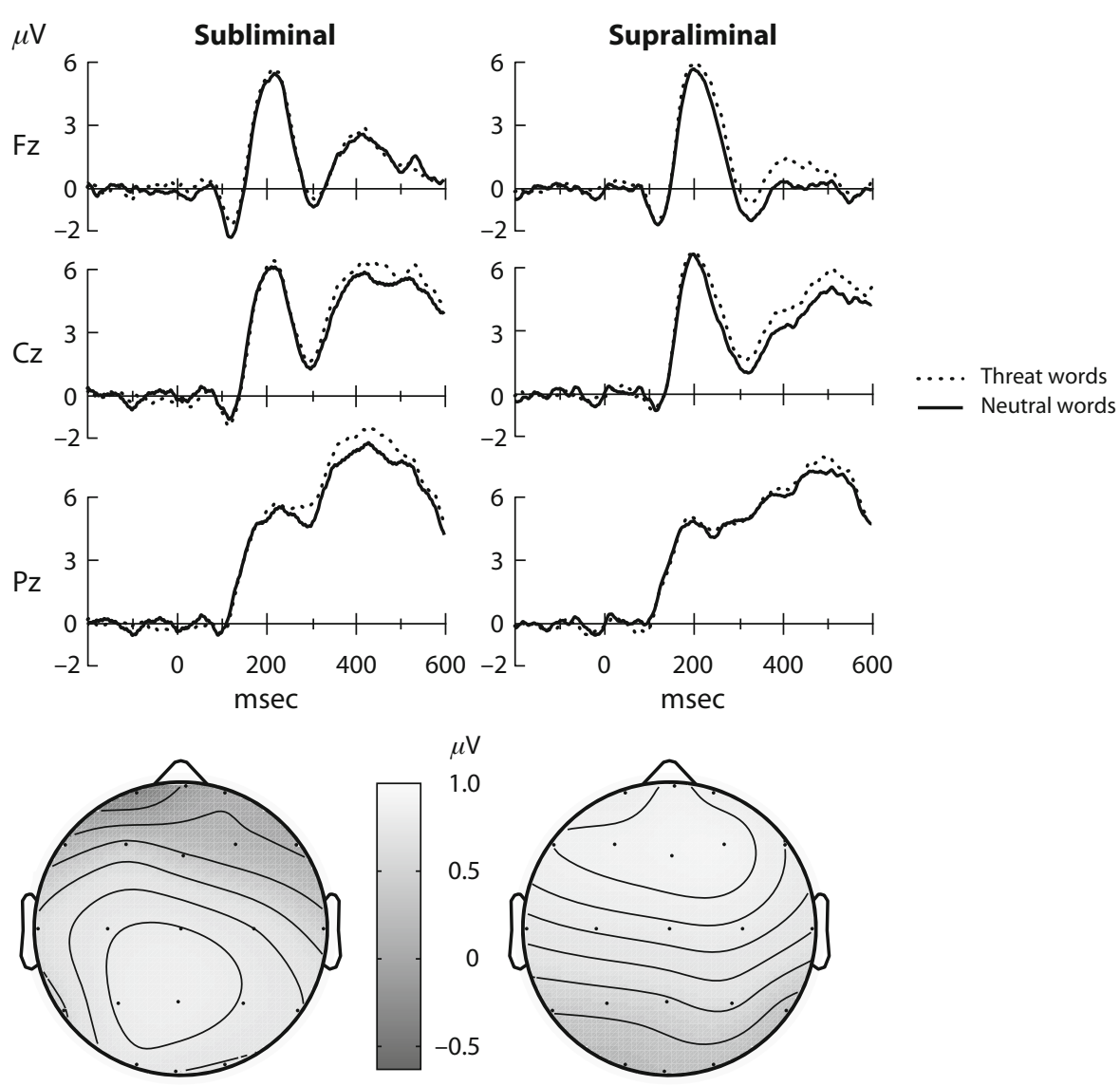

Figure 3. ERP waveforms to subliminal and supraliminal neutral and threat words at $\mathrm{Fz}, \mathrm{Cz}$, and $\mathrm{Pz}$, along with topographies of ERP differences (threat - neutral) over the 300- to 500-msec interval for the two conditions.

Subliminal processing of threat was investigated by applying backward masking to word stimuli. In the present experiment, we use the term subliminal to describe word processing when words were presented at an SOA at least $25 \%$ below each participant's individually assessed threshold for word identification, and we use the term unconscious to describe word processing when participants denied seeing these words throughout the experiment on the basis of trial-by-trial assessments. Use of subjective measures of conscious experience, as in the present design, has previously been advocated as a suitable way to confirm unconscious processing (Mayer \& Merckelbach, 1999; Merikle, Smilek, \& Eastwood, 2001). A problem with subjective measures of conscious awareness, however, is that they can be influenced by a person's willingness or unwillingness to report words seen with low confidence. We strongly encouraged each participant to venture a guess for any words that they could have possibly seen; we also encouraged them to report any word they became aware of even after seeing the matching stem in the last phase of the experiment. Therefore, although we cannot rule out the possibility that some subjects may have experienced some fleeting awareness of one or more subliminal words, we regard this possibility as largely inconsequen- tial, given that ERP averaging weights each trial equally (i.e., ERP effects observed based on roughly 100 trials, as in the present study, are unlikely to arise solely from differential responses on just a few trials). Furthermore, ERP effects in the subliminal condition did not appear to be smaller versions of ERP effects in the supraliminal condition. Qualitative differences in late ERP patterns for subliminal versus supraliminal conditions thus provides additional validation for this manipulation (Hannula, Simons, \& Cohen, 2005).

\section{Relatively Early Threat Processing}

Despite the extreme difficulty the participants experienced in seeing the subliminal words, brain potentials showed evidence of differential word processing based on meaning. Early differential processing of threat versus neutral words as a function of TA was evidenced through analysis of occipital P1 potentials, which on average peaked $130 \mathrm{msec}$ poststimulus. Importantly, this effect appeared regardless of exposure type. Presumably, both conscious and unconscious threat processing could occur in the supraliminal condition, whereas only unconscious threat processing could occur in the subliminal condition. The fact that this P1 effect was independent of exposure 
type $[F(1,28)=.02, p=.88]$ suggests that the processing reflected by early $\mathrm{P} 1$ differences does not rely on conscious perception of stimuli and can thus occur unconsciously. ${ }^{3}$ Our findings therefore lend additional support to the notion that early differences in electrophysiological responses to threat versus neutral information reflect automatic preferential threat processing (see, e.g., Holmes et al., 2003; Pizzagalli et al., 2002; Pizzagalli et al., 1999; Smith et al., 2003) and also show that such effects are modulated by TA.

The systematic influence of TA status on early unconscious processing of threat supports the conjecture that early threat processing is enhanced among anxious individuals (Mathews \& MacLeod, 1994; J. M. G. Williams et al., 1997). Those participants with high TA in our experiment tended to show larger P1 amplitudes for threat than for neutral words. Moreover, the influence of TA on P1 effects may account for the apparent conflict in the literature concerning differential $\mathrm{P} 1$ responses to emotional stimuli. Emotion effects on P1 tend to vary widely across studies. Liked faces, for example, elicited a greater P1 than disliked faces (Pizzagalli et al., 1999), whereas in another study disliked faces elicited a greater P1 than liked faces (Pizzagalli et al., 2002). Often, there is no effect of threat on grand average P1 potentials (see, e.g., Eimer \& Holmes, 2002; Schupp et al., 2003; Schupp et al., 2004). Rather, P1 effects appeared in opposite directions for highTA and low-TA participants (Figure 2). Accordingly, we speculate that effects of emotional valence are not apparent when results from high- and low-TA participants cancel each other out, whereas a preponderance of relatively high- or low-TA participants may yield an effect in one direction or the other. Recent fMRI studies also showed crossover interactions between individual differences in risk for anxiety (based on personality or genotype) and stimulus valence (threat vs. neutral) on amygdala activation (Figure 3A of Etkin et al., 2004; Figure 1A of Heinz et al., 2005), echoing many behavioral studies exhibiting opposite preference of threat versus neutral information among high- and low-anxiety people (e.g., MacLeod \& Rutherford, 1992; Mathews \& Sebastian, 1993; Van den Hout et al., 1995). Hence, we suggest that individual differences in TA should be considered when threat processing is investigated in typical samples of healthy individuals.

Fast, unconscious perception of threat may take place via a subcortical (colliculo-pulvinar-amygdala) pathway proposed on the basis of research in animals (LeDoux, 1995) and humans (de Gelder, Morris, \& Dolan, 2005; Liddell et al., 2005; Morris, de Gelder, Weiskrantz, \& Dolan, 2001; Morris, Öhman, \& Dolan, 1999), with the exception of Pessoa et al. (2002; also see Pessoa, 2005; Pessoa, Japee, \& Ungerleider, 2005). Projections from the amygdala subsequently influence responses in fusiform gyrus and extrastriate cortex (Amaral, Price, Pitkanen, \& Carmichael, 1992; LeDoux, 1995), including the region where P1 is thought to be generated (Gomez et al., 1994; Mangun et al., 1993; Pourtois et al., 2004). Amygdala projections can presumably facilitate visual perception regardless of conscious awareness of stimuli (Morris,
Öhman, \& Dolan, 1998, 1999; Vuilleumier et al., 2004). Interestingly, anxiety can amplify amygdala activation to threat even when stimuli are subliminal (see, e.g., Etkin et al., 2004; Rauch et al., 2000; Stein, Goldin, Sareen, Zorrilla, \& Brown, 2002). Recent evidence suggests that enhanced amygdala response occurs to both positive and negative stimuli, provided that they are highly arousing (Anderson et al., 2003; Small et al., 2003; Winston, Gottfried, Kilner, \& Dolan, 2005; also see Anderson, 2005, and Schimmack \& Derryberry, 2005, for behavioral evidence). However, we suggest that the modulatory role of anxiety is particularly potent for threat processing, given that anxiety and threat both carry negative affect. Future research with both threat and positive stimuli may provide direct evidence concerning this question. On the whole, these subcortical pathways provide a putative anatomical basis for the P1 effects observed here-namely, facilitated automatic/unconscious threat processing in anxiety.

An important feature of the present study is that the threat stimuli were words. Two studies of fear-potentiated startle also showed that lexical threat information can elicit very fast (90-100 msec poststimulus) preferential processing, which varied as a function of anxiety (Aitken, Siddle, \& Lipp, 1999; Waters, Lipp, \& Cobham, 2000). However, nonverbal stimuli were used in most studies of early ERP differences elicited by threat. Differential responses to emotional versus neutral faces were found prior to N170, a component often taken to index the structural encoding of faces (Bentin, Allison, Puce, Perez, \& McCarthy, 1996; Eimer, 2000). Indeed, faces can readily elicit emotion effects even via isolated features such as eyebrows or eye whites (Lundqvist, Esteves, \& Öhman, 1999; Whalen et al., 2004). Therefore, coarse and partial processing of faces (or other pictures) may contribute to extremely fast emotional discrimination. It is intriguing that emotional discrimination based on words could also occur so quickly; further research is needed to understand the mechanism behind this apparently very swift lexicalsemantic processing.

\section{Relatively Late Threat Processing}

At a relatively late stage, threat led to increased ERP amplitudes, most prominently in the interval of 300500 msec. In keeping with the literature on P3 potentials, greater P3 amplitudes were associated with faster color discrimination responses, which suggests that P3 in the present study indexed processing of font color, at least in part. Furthermore, P3 to threat was augmented in both supraliminal and subliminal conditions, but with distinct topographic patterns and associations with TA: a frontal focus and no evidence of an association with TA in the supraliminal condition, and a parietal focus and positive correlation with TA in the subliminal condition.

P3 potentials peaked earlier in the subliminal condition than in the supraliminal condition, presumably because controlled resources were allocated primarily to color processing as opposed to both color and word processing. Nonetheless, ERPs at centroparietal locations were also modulated by subliminal threat, especially among the high-TA participants. We speculate that this influence 
of word meaning on late processing may constitute an automatic outcome of subliminal threat input, which, in contrast, was largely shut down in the supraliminal condition due to strategic efforts to maintain attention on colornaming processing.

Given that the amygdala can swiftly modulate neocortical processing (Hariri, Mattay, Tessitore, Fera, \& Weinberger, 2003; LeDoux, 1995, 1996), we speculate that subliminal threat processing, as indexed here in part by parietal P3 amplitude differences, may have been influenced by amygdala input to cortex. However, one cannot discriminate whether threat influenced parietal $\mathrm{P} 3$ potentials directly or other ERPs in the 300-500-msec interval. In two prior studies in which behavioral responses were not required, effects of subliminal threat were not observed in late parietal ERPs (Liddell et al., 2004; L. M. Williams et al., 2004). Speeded behavioral responses such as those required in the present study may thus perpetuate the effect of threat on parietal ERPs, but such speculations merit additional experimentation with subliminal threat stimuli.

In the supraliminal condition, threat-minus-neutral ERP differences exhibited a unique frontal topography. This frontal effect may reflect dynamic interactions between automatic processing of threat words and a strategic suppression of distraction so as to maintain task-relevant processing. An outcome of this strategic influence may be that attentional resources are effectively maintained on color information. In other words, frontally mediated strategic suppression of distraction may have virtually eliminated automatic threat processing that would otherwise have been apparent in late parietal ERPs. A small threat $>$ neutral difference at around $500 \mathrm{msec}$ in parietal ERPs is consistent with the notion of reduced and delayed emotion processing as the result of suppression. Larger and earlier ERP effects of this sort can occur in the absence of topdown inhibition, as in the subliminal condition and when emotion processing is task relevant (see, e.g., Cuthbert et al., 2000; Eimer \& Holmes, 2002; Holmes et al., 2003; Schupp et al., 2003; Schupp et al., 2004).

Another possible explanation for the frontal effect in the supraliminal condition must also be considered. Conscious word comprehension is typically thought to engage N400-like potentials that could be larger for neutral words than for threat words, given that neutral words received less conceptual priming than did threat words (Kutas \& Federmeier, 2000; Voss \& Paller, 2006). This possibility is also consistent with the reduced late frontal positivity in the supraliminal versus the subliminal condition. It is also reasonable to suppose that the supraliminal condition included more processing of word meaning as well as more strategic suppression of emotion processing than did the subliminal condition.

Additional insights concerning dynamic interactions between emotion and cognitive analysis can be drawn from fMRI studies in which the supraliminal emotional Stroop task was used. Compton et al. (2003) demonstrated greater activation of dorsolateral prefrontal cortex (DLPFC) to threat words than to neutral words. The fact that this region showed response enhancement to both incongruent color words (classical Stroop) and threat words (emotional Stroop) led the authors to argue that DLPFC executed enhanced selective attention in the presence of emotionally salient distractors, resulting in the absence of greater RT delay for threat than for neutral words (similar to what we observed in the supraliminal condition in our study). Consonant findings were obtained using a variant of the emotional Stroop task, in that anterior cingulate cortex was more active to threat words than to neutral words whereas RTs in threat and in neutral trials did not differ (Whalen et al., 1998). Additional evidence from studies in which supraliminal threat and neutral faces were used as distractors also showed that rostral cingulate cortex was more activated by threat than by neutral stimuli (Bishop, Duncan, Brett, \& Lawrence, 2004; Vuilleumier, Armony, Driver, \& Dolan, 2001). On the whole, these data suggest that frontal activation was increased on threat trials, which allowed for enhanced cognitive control over distraction and facilitated task-relevant processing.

\section{Behavioral Responses in the Emotional Stroop Task}

Color discrimination RTs established that word processing per se competed for resources with color processing, resulting in longer RTs to words than to symbols whether the words were supraliminal or subliminal. Word valence and exposure condition affected color naming interactively: Responses tended to be faster to threat than to neutral words in the subliminal condition, whereas they tended to be slower to threat than to neutral words in the supraliminal condition, although both these trends were nonsignificant. The significant interaction nonetheless provided further support for the qualitative difference between subliminal and supraliminal conditions. As in many prior emotional Stroop studies with healthy individuals, RT interference bias to threat was not present (e.g., Compton et al., 2003; Martin, Williams, \& Clark, 1991; Whalen et al., 1998), nor was it associated with TA (e.g., Etkin et al., 2004; Martin et al., 1991). These negative findings might be due to conflicting processes (e.g., strategic control, automatic threat processing) that cancel each other out by the time the behavioral response occurs (Compton et al., 2003; Mogg \& Bradley, 1998; J. M. G. Williams et al., 1996). Therefore, the present results suggest that ERPs might be superior to RT measures for parsing multiple processes and capturing the valence effect and its association with TA.

\section{Conclusions}

In sum, P1 potentials demonstrated preferential analysis of threat that occurred at an early perceptual stage, did not require word awareness, and were more prominent the higher the level of TA. Late threat processing also took place in both exposure conditions, even though threat information was irrelevant to the assigned task. Importantly, different mechanisms were implicated in this late threat processing depending on whether words were processed consciously or unconsciously. These findings further corroborate the qualitative distinction between supraliminal 
and subliminal conditions in our experiment. A prolonged frontal threat $>$ neutral ERP effect in the supraliminal condition may have signaled that strategic control was engaged to override analysis of word meaning, especially for threat words. Late potentials apparently indexed task-related processing of font color generally, given that larger amplitudes were associated with shorter RTs. Processing supraliminal word meaning presumably pulled resources away from processing font color, resulting in smaller late potential amplitudes for supraliminal than for subliminal words. For subliminal words, a late centroparietal threat $>$ neutral ERP effect, which varied as a function of anxiety, hints that preferential processing of unconscious threat continues at a later stage due to a default threat bias and lack of volitional top-down inhibition. These findings implicate different types of threat analysis at different perceptual stages and also shed light on emotional biases that might be relevant in the development and maintenance of anxiety.

\section{AUTHOR NOTE}

This research was supported by National Institutes of Health Grant NS 34639 and National Science Foundation Grant BCS-0518800. We thank Karuna Subramaniam for assistance with data collection and Stephan Boehm, Sue Mineka, Bill Revelle, Peter Rosenfeld, and Marty Woldorff for advice and comments. Correspondence concerning this article should be addressed to W. Li, Northwestern University Institute for Neuroscience, 320 E. Superior St., Searle 11-453, Chicago, IL 60611 (e-mail: wenli@northwestern.edu).

\section{REFERENCES}

Aitken, C. J., Siddle, D. T., \& Lipp, O. (1999). The effects of threat and nonthreat word lead stimuli on blink modification. Psychophysiology, 36, 699-705.

Amaral, D. G., Price, J. L., Pitkanen, A., \& Carmichael, S. T. (1992). Anatomical organization of the primate amygdaloid complex. In J. P. Aggleton (Ed.), The amygdala: Neurobiological aspects of emotion, memory and mental dysfunction (pp. 1-66). New York: Wiley-Liss.

Anderson, A. K. (2005). Affective influences on the attentional dynamics supporting awareness. Journal of Experimental Psychology: General, 134, 258-281.

Anderson, A. K., Christoff, K., Stappen, I., Panitz, D., GhahreMani, D. G., Glover, G., ET AL. (2003). Dissociated neural representations of intensity and valence in human olfaction. Nature Neuroscience, 6, 196-202.

BECK, D. C. (1975). Electrophysiology and behavior. Annual Review of Psychology, 26, 233-262.

Bentin, S., Allison, T., Puce, A., Perez, A., \& McCarthy, G. (1996). Electrophysiological studies of face perception in humans. Journal of Cognitive Neuroscience, $8,551-565$.

Bishop, S., Duncan, J., Brett, M., \& Lawrence, A. D. (2004). Prefrontal cortical function and anxiety: Controlling attention to threatrelated stimuli. Nature Neuroscience, 7, 184-188.

Bradley, B. [P.], \& Mathews, A. (1983). Negative self-schemata in clinical depression. British Journal of Clinical Psychology, 22, 173-181.

Bradley, B. P., Mogg, K., Millar, N., \& White, J. (1995). Selective processing of negative information: Effects of clinical anxiety, concurrent depression, and awareness. Journal of Abnormal Psychology, 104, 532-536.

CARVER, C. S., \& White, T. L. (1994). Behavioral inhibition, behavioral activation, and affective responses to impending reward and punishment: The BIS/BAS scales. Journal of Personality \& Social Psychology, 67, 319-333.

ClaRK, D. M. (1988). A cognitive model of panic attacks. In S. Rachman \& J. D. Maser (Eds.), Panic: Psychological perspectives (pp. 71-89). Hillsdale, NJ: Erlbaum.
Compton, R. J., Banich, M. T., Mohanty, A., Milham, M. P., Herrington, J., Miller, G. A., et AL. (2003). Paying attention to emotion: An fMRI investigation of cognitive and emotional Stroop tasks. Cognitive, Affective, \& Behavioral Neuroscience, 3, 81-96.

Cuthbert, B. N., Schupp, H. T., Bradley, M. M., Birbaumer, N., \& LANG, P. J. (2000). Brain potentials in affective picture processing: Covariation with autonomic arousal and affective report. Biological Psychology, 52, 95-111.

Damasio, A. R. (1994). Descartes' error: Emotion, reason and the human brain. New York: Putnam.

Davidson, R. J. (1998). Affective style and affective disorders: Perspectives from affective neuroscience. Cognition \& Emotion, 12, 307-320.

Davis, M., \& Whalen, P. J. (2001). The amygdala: Vigilance and emotion. Molecular Psychiatry, 6, 13-34.

DE Gelder, B., Morris, J. S., \& Dolan, R. J. (2005). Unconscious fear influences emotional awareness of faces and voices. Proceedings of the National Academy of Sciences, 102, 18682-18687.

Dietrich, D. E., Emrich, H. M., Waller, C., Wieringa, B. M., JohanNES, S., \& MunTe, T. F. (2000). Emotion/cognition-coupling in word recognition memory of depressive patients: An event-related potential study. Psychiatry Research, 96, 15-29.

Dolan, R. [J.] (2002). Emotion, cognition, and behavior. Science, 298, 1191-1194.

Dolan, R. J., \& Vuilleumier, P. (2003). Amygdala automaticity in emotional processing. Annals of the New York Academy of Sciences, 985, 348-355.

Donchin, E., \& Coles, M. G. (1988). Is the P300 component a manifestation of context updating? Behavioral \& Brain Sciences, 11, 357-427.

EIMER, M. (2000). Event-related brain potentials distinguish processing stages involved in face perception and recognition. Clinical Neurophysiology, 111, 694-705.

EIMER, M., \& Holmes, A. (2002). An ERP study on the time course of emotional face processing. NeuroReport, 13, 427-431.

Etkin, A., Klemenhagen, K. C., Dudman, J. H., Rogan, M. T., Hen, R., KANDEL, E. R., \& HiRsch, J. (2004). Individual differences in trait anxiety predict the response of the basolateral amygdala to unconsciously processed fearful faces. Neuron, 44, 1043-1055.

Fox, E. (2002). Processing emotional facial expressions: The role of anxiety and awareness. Cognitive, Affective, \& Behavioral Neuroscience, 2, 52-63.

Gomez, G. C. M., Clark, V. P., Fan, S., Luck, S. J., \& Hillyard, S. A. (1994). Sources of attention-sensitive visual event-related potentials. Brain Topography, 7, 41-51.

Halgren, E., \& Marinkovic, K. (1995). Neurophysiological networks integrating human emotions. In M. Gazzaniga (Ed.), The cognitive neurosciences (pp. 1137-1151). Cambridge, MA: MIT Press.

Halgren, E., RaiJ, T., Marinkovic, K., Jousmaki, V., \& Hari, R. (2000). Cognitive response profile of the human fusiform face area as determined by MEG. Cerebral Cortex, 10, 69-81.

Hannula, D. E., Simons, D. J., \& Cohen, N. J. (2005). Imaging implicit perception: Promise and pitfalls. Nature Reviews Neuroscience, 6, 247-255.

Hariri, A. R., Mattay, V. S., Tessitore, A., Fera, F., \& Weinberger, D. R. (2003). Neocortical modulation of the amygdala response to fearful stimuli. Biological Psychiatry, 53, 494-501.

Heinz, A., Braus, D. F., Smolka, M. N., Wrase, J., Puls, I., HermanN, D., ET AL. (2005). Amygdala-prefrontal coupling depends on a genetic variation of the serotonin transporter. Nature Neuroscience, 8, 20-21.

Hillyard, S. A., Squires, K. C., Bauer, J. W., \& Lindsay, P. H. (1971). Evoked potential correlates of auditory signal detection. Science, 172, 1357-1360.

Holmes, A., Vuilleumier, P., \& Eimer, M. (2003). The processing of emotional facial expression is gated by spatial attention: Evidence from event-related brain potentials. Cognitive Brain Research, 16, 174-184.

Ito, T. A., Larsen, J. T., Smith, N. K., \& CaCioppo, J. T. (1998). Negative information weighs more heavily on the brain: The negativity bias in evaluative categorizations. Journal of Personality \& Social Psychology, 75, 887-900. 
JASPER, H. H. (1958). The ten-twenty electrode system of the International Federation. Electroencephalography of Clinical Neurophysiology, 10, 371-375.

Johansson, S., \& Hofland, K. (1989). Frequency analysis of English vocabulary and grammar: Based on the LOB corpus. Oxford: Oxford University Press.

Johnston, V. S., Miller, D. R., \& Burleson, M. H. (1986). Multiple P3s to emotional stimuli and their theoretical significance. Psychophysiology, 23, 684-694.

Kutas, M., \& Federmeier, K. D. (2000). Electrophysiology reveals semantic memory use in language comprehension. Trends in Cognitive Sciences, 4, 463-470.

LaBar, K. S., Rabinovici, G. D., Ranganath, C., Gitelman, D. R., Parrish, T. B., Paller, K. A., \& Mesulam, M.-M. (1999). Spatiotemporal dynamics of a neural network for emotional picture encoding revealed by parallel evoked potential and fMRI measurements. Society for Neuroscience Abstracts, 25, 2146.

Lang, P. J., Bradley, M. M., \& Cuthbert, B. N. (1997). Motivated attention: Affect, activation, and action. In P. J. Lang, R. F. Simons, \& M. T. Balaban (Eds.), Attention and orienting: Sensory and motivational processes (pp. 97-135). Mahwah, NJ: Erlbaum.

Lang, P. J., Davis, M., \& Öhman, A. (2000). Fear and anxiety: Animal models and human cognitive psychophysiology. Journal of Affective Disorders, 61, 137-159.

LeDoux, J. E. (1995). Emotion: Clues from the brain. Annual Review of Psychology, 46, 209-235.

LeDoux, J. E. (1996). The emotional brain: The mysterious underpinnings of emotional life. New York: Simon \& Schuster.

Li, W., PAller, K. A., \& Zinbarg, R. E. (in press). Unconcious priming of threat words varies with trait anxiety. Cognition \& Emotion.

Li, W., Zinbarg, R. E., Boehm, S. G., \& Paller, K. A. (in press). Neural and behavioral evidence for affective priming from unconsciously perceived emotional facial expressions and the influence of trait anxiety. Journal of Cognitive Neuroscience.

Liddell, B. J., Brown, K. J., Kemp, A. H., Barton, M. J., Das, P., Peduto, A., ET AL. (2005). A direct brainstem-amygdala-cortical "alarm" system for subliminal signals of fear. NeuroImage, $\mathbf{2 4}$, 235-243.

Liddell, B. J., Williams, L. M., Rathjen, J., Shevrin, H., \& Gordon, E. (2004). A temporal dissociation of subliminal versus supraliminal fear perception: An event-related potential study. Journal of Cognitive Neuroscience, 16, 479-486.

Lundqvist, D., Esteves, F., \& Öhman, A. (1999). The face of wrath: Critical features for conveying facial threat. Cognition \& Emotion, 13, 691-711.

MacLeod, C., \& Rutherford, E. M. (1992). Anxiety and the selective processing of emotional information: Mediating roles of awareness, trait and state variables, and personal relevance of stimulus materials. Behaviour Research \& Therapy, 30, 479-491.

Mangun, G. R., Hillyard, S. A., \& Luck, S. L. (1993). Electrocortical substrates of visual selective attention. In D. E. Meyer \& S. Kornblum (Eds.), Attention and performance XIV: Synergies in experimental psychology, artificial intelligence, and cognitive neuroscience (pp. 219243). Cambridge, MA: MIT Press.

Martin, M., Williams, R. M., \& Clark, D. M. (1991). Does anxiety lead to selective processing of threat-related information? Behavior Research \& Therapy, 29, 147-160.

Mathews, A. [M.], \& MacLeod, C. (1985). Selective processing of threat cues in anxiety states. Behaviour Research \& Therapy, 23, 563-569.

Mathews, A. [M.], \& MacLeod, C. (1986). Discrimination of threat cues without awareness in anxiety states. Journal of Abnormal Psychology, 95, 131-138.

Mathews, A. [M.], \& MacLeod, C. (1994). Cognitive approaches to emotion and emotional disorders. Annual Review of Psychology, 45, 25-50.

Mathews, A. [M.], Mogg, K., May, J., \& Eysenck, M. (1989). Implicit and explicit memory bias in anxiety. Journal of Abnormal Psychology, 98, 236-240.

Mathews, A. M., \& Sebastian, S. (1993). Suppression of emotional Stroop effect by fear arousal. Cognition \& Emotion, 7, 517-530.

Mayer, B., \& Merckelbach, H. (1999). Unconscious processes, sub- liminal stimulation, and anxiety. Clinical Psychology Review, 19, 571-590.

McCARthy, G., \& Wood, C. C. (1985). Scalp distributions of eventrelated potentials: An ambiguity associated with analysis of variance models. Electroencephalography \& Clinical Neurophysiology, 62, 203-208.

Merikle, P. M., Smilek, D., \& Eastwood, J. D. (2001). Perception without awareness: Perspectives from cognitive psychology. Cognition, 79, 115-134.

Mogg, K., \& Bradley, B. P. (1998). A cognitive-motivational analysis of anxiety. Behaviour Research \& Therapy, 36, 809-848.

Morris, J. S., De Gelder, B., Weiskrantz, L., \& Dolan, R. J. (2001). Differential extrageniculostriate and amygdala responses to presentation of emotional faces in a cortically blind field. Brain, 124, 1241-1252.

Morris, J. S., Öhman, A., \& Dolan, R. J. (1998). Conscious and unconscious emotional learning in the human amygdala. Nature, 393, 467-470.

Morris, J. S., Öhman, A., \& Dolan, R. J. (1999). A subcortical pathway to the right amygdala mediating "unseen" fear. Proceedings of the National Academy of Sciences, 96, 1680-1685.

Naumann, E., Bartussek, D., Diedrich, O., \& Laufer, M. E. (1992). Assessing cognitive and affective information processing functions of the brain by means of the late positive complex of the event-related potential. Journal of Psychophysiology, 6, 285-298.

Naumann, E., Maier, S., Diedrich, O., Becker, G., \& Bartussek, D. (1997). Structural, semantic, and emotion-focused processing of neutral and negative nouns: Event-related potential correlates. Journal of Psychophysiology, 11, 158-172.

Öhman, A. (1979). The orienting response, attention, and learning: An information processing perspective. In H. D. Kimmel, E. H. van Olst, \& J. R. Orlebeke (Eds.), The orienting reflex in humans (pp. 443-472). Hillsdale, NJ: Erlbaum.

Öhman, A. (1993). Fear and anxiety as emotional phenomena: Clinical phenomenology, evolutionary perspectives, and informationprocessing mechanisms. In M. Lewis \& J. M. Haviland (Eds.), Handbook of emotions (pp. 511-536). New York: Guilford.

Öhman, A., \& MineKa, S. (2001). Fears, phobias, and preparedness: Toward an evolved module of fear and fear learning. Psychological Review, 108, 483-522.

Öhman, A., \& Soares, J. J. F. (1994). "Unconscious anxiety": Phobic responses to masked stimuli. Journal of Abnormal Psychology, 103, 231-240.

Palomba, D., Angrilli, A., \& Mini, A. (1997). Visual evoked potentials, heart rate responses and memory to emotional pictorial stimuli. International Journal of Psychophysiology, 27, 55-67.

PessoA, L. (2005). To what extent are emotional visual stimuli processed without attention and awareness? Current Opinion in Neurobiology, 15, 188-196.

Pessoa, L., Japee, S., \& Ungerleider, L. G. (2005). Visual awareness and the detection of fearful faces. Emotion, 5, 243-247.

Pessoa, L., McKenna, M., Gutierrez, E., \& Ungerleider, L. G. (2002). Neural processing of emotional faces requires attention. Proceedings of the National Academy of Sciences, 99, 11458-11463.

Phelps, E. A. (2006). Emotion and cognition: Insights from studies of the human amygdala. Annual Review of Psychology, 57, 27-53.

Pizzagalli, D. A., Lehmann, D., Hendrick, A. M., Regard, M., Pascual-Marqui, R. D., \& Davidson, R. J. (2002). Affective judgments of faces modulate early activity (approximately $160 \mathrm{~ms}$ ) within the fusiform gyri. NeuroImage, 16, 663-677.

Pizzagalli, D. [A.], Regard, M., \& Lehmann, D. (1999). Rapid emotional face processing in the human right and left brain hemispheres: An ERP study. NeuroReport, 10, 2691-2698.

Pourtois, G., Grandjean, D., Sander, D., \& Vuilleumier, P. (2004) Electrophysiological correlates of rapid spatial orienting towards fearful faces. Cerebral Cortex, 14, 619-633.

Rauch, S. L., Whalen, P. J., Shin, L. M., McInerney, S. C., MackLIN, M. L., LASKO, N. B., ET AL. (2000). Exaggerated amygdala response to masked facial stimuli in posttraumatic stress disorder: A functional MRI study. Biological Psychiatry, 47, 769-776.

RitTER, W., \& RUCHKIN, D. S. (1992). A review of event-related poten- 
tial components discovered in the context of studying P3. Annals of the New York Academy of Sciences, 658, 1-32.

Schimmack, U., \& Derryberry, D. (2005). Attentional interference effects of emotional pictures: Threat, negativity, or arousal? Emotion, 5, 55-66.

Schupp, H. T., Cuthbert, B. N., Bradley, M. M., Caciopro, J. T., Ito, T., \& LANG, P. J. (2000). Affective picture processing: The late positive potential is modulated by motivational relevance. Psychophysiology, 37, 257-261.

SChUPp, H. T., Junghöfer, M., Weike, A. I., \& Hamm, A. O. (2003). Attention and emotion: An ERP analysis of facilitated emotional stimulus processing. NeuroReport, 14, 1107-1110.

Schupp, H. T., Öhman, A., Junghöfer, M., Weike, A. I., StockBURGER, J., \& HAMm, A. O. (2004). The facilitated processing of threatening faces: An ERP analysis. Emotion, 4, 189-200.

Small, D. M., Gregory, M. D., Mak, Y. E., Gitelman, D., Mesulam, M. M., \& PARrish, T. (2003). Dissociation of neural representation of intensity and affective valuation in human gustation. Neuron, 39, 701-711.

Smith, N. K., Cacioppo, J. T., Larsen, J. T., \& Chartrand, T. L. (2003). May I have your attention, please: Electrocortical responses to positive and negative stimuli. Neuropsychologia, 41, 171-183.

SPIELBERGER, C. D. (1983). Manual for the State-Trait Anxiety Inventory (STAI). Palo Alto, CA: Consulting Psychologists Press.

Stein, M. B., Goldin, P. R., Sareen, J., Zorrilla, L. T. E., \& Brown, G. G. (2002). Increased amygdala activation to angry and contemptuous faces in generalized social phobia. Archives of General Psychiatry, 59, 1027-1034.

TAYLOR, J. A. (1953). A personality scale of manifest anxiety. Journal of Abnormal \& Social Psychology, 48, 285-290.

Van den Hout, M., Tenney, N., Huygens, K., Merckelbach, H., \& KINDT, M. (1995). Responding to subliminal threat cues is related to trait anxiety and emotional vulnerability: A successful replication of Macleod and Hagan (1992). Behaviour Research \& Therapy, 33, 451-454.

Voss, J. L., \& Paller, K. A. (2006). Fluent conceptual processing and explicit memory for faces are electrophysiologically distinct. Journal of Neuroscience, 26, 926-933.

Vuilleumier, P., Armony, J. L., Driver, J., \& Dolan, R. J. (2001). Effects of attention and emotion on face processing in the human brain: An event-related fMRI study. Neuron, 30, 829-841.

Vuilleumier, P., Armony, J. L., Driver, J., \& Dolan, R. J. (2003). Distinct spatial frequency sensitivities for processing faces and emotional expressions. Nature Neuroscience, 6, 624-631.

Vuilleumier, P., Richardson, M. P., Armony, J. L., Driver, J., \& Dolan, R. J. (2004). Distant influences of amygdala lesion on visual cortical activation during emotional face processing. Nature Neuroscience, 7, 1271-1278.

Waters, A. M., Lipp, O. V., \& Совнам, V. E. (2000). Investigation of threat-related attentional bias in anxious children using the startle eyeblink modification paradigm. Journal of Psychophysiology, 14, $142-150$

West, S. G., Aiken, L. S., \& Krull, J. L. (1996). Experimental personality designs: Analyzing categorical by continuous variable interactions. Journal of Personality, 64, 1-48.

Whalen, P. J., Bush, G., McNally, R. J., Wilhelm, S., McInerney, S. C., JeNIKE, M. A., \& RAUCH, S. L. (1998). The emotional counting Stroop paradigm: A functional magnetic resonance imaging probe of the anterior cingulate affective division. Biological Psychiatry, 44, $1219-1228$

Whalen, P. J., Kagan, J., Cook, R. G., Davis, F. C., Kim, H., Polis, S., ET AL. (2004). Human amygdala responsivity to masked fearful eye whites. Science, 306, 2061.

Whalen, P. J., Rauch, S. L., Etcoff, N. L., Mcinerney, S. C., Lee, M. B., \& JeNIKE, M. A. (1998). Masked presentations of emotional facial expressions modulate amygdala activity without explicit knowledge. Journal of Neuroscience, 18, 411-418.

Williams, J. M. G., Mathews, A., \& MacLeod, C. (1996). The emotional Stroop task and psychopathology. Journal of Abnormal Psychology, 120, 3-24.

Williams, J. M. G., Watts, F. N., MacLeod, C., \& Mathews, A. (1997). Cognitive psychology and emotional disorders (2nd ed.). Chichester: Wiley.

Williams, L. M., Liddell, B. J., Rathjen, J., Brown, K. J., Gray, J., Phillips, M., ET AL. (2004). Mapping the time course of nonconscious and conscious perception of fear: An integration of central and peripheral measures. Human Brain Mapping, 21, 64-74.

Winston, J. S., GotTfried, J. A., Kilner, J. M., \& Dolan, R. J. (2005). Integrated neural representations of odor intensity and affective valence in human amygdala. Journal of Neuroscience, 25, 8903-8907.

ZinbarG, R. E., \& Mohlman, J. (1998). Individual differences in the acquisition of affectively valenced associations. Journal of Personality \& Social Psychology, 74, 1024-1040.

\section{NOTES}

1. We also conducted repeated measures ANOVAs wherein each participant was assigned to a high- or a low-TA group on the basis of his or her BIS score. We obtained results that were entirely consistent with the regression analysis results.

2. Similar P1 results were obtained at $\mathrm{O} 1$ and $\mathrm{O} 2(r=.40, p<.05$, and $r=.32, p=.08$, respectively)

3. Recently, we extended these findings by showing that P1 was enhanced for subliminal fearful faces versus subliminal happy faces and that the augmentation of P1 was influenced by TA (Li, Zinbarg, Boehm, $\&$ Paller, in press), although no supraliminal stimulus presentation condition was included. 
APPENDIX A

Threat and Neutral Words Used As Stimuli

\begin{tabular}{lll}
\hline \multicolumn{1}{c}{ Set A } & Set B & Set C \\
\hline & Threat Words & \\
grieve & mutilate & panicky \\
unloved & persecuted & strangle \\
devastate & blunder & fright \\
gloomy & casualty & incurable \\
punish & torment & lethal \\
ridicule & ambulance & paralysis \\
collapse & corpse & insult \\
reject & dread & wretched \\
sinister & assault & horror \\
hostile & fatal & tumor \\
cancer & crash & terror \\
funeral & wound & defeat \\
grave & suffer & tragic \\
accident & violent & destroy \\
murder & disease & danger \\
enemy & attack & failure \\
& Neutral Words & \\
geometry & bungalow & \\
divert & washer & subscribe \\
sluggish & formality & brochure \\
pastel & celery & multitude \\
flannel & tomato & claret \\
genial & racket & adapt \\
tapestry & feather & revise \\
apprehend & junction & elephant \\
absorb & carpet & drawer \\
fountain & battery & integral \\
holder & garage & convey \\
quantity & museum & remark \\
shear & furniture & campus \\
decade & mantle & thermal \\
league & sharp & domestic \\
record & bottle & exchange \\
& & bridge \\
\hline & & \\
& &
\end{tabular}

APPENDIX B

Mean Word Length (in Letters) and Mean Word Frequency (per Million) of Threat and Neutral Words Used As Stimuli

\begin{tabular}{lcc}
\hline Stimulus Words & Length & Frequency \\
\hline Threat & & \\
Set A & 6.75 & 21.75 \\
Set B & 6.69 & 21.06 \\
Set C & 6.75 & 22.50 \\
Neutral & & \\
Set A & 6.81 & 25.81 \\
Set B & 6.63 & 21.88 \\
Set C & 6.94 & 24.30 \\
\hline
\end{tabular}

(Manuscript received August 21, 2005;

revision accepted for publication September 6, 2006.) 